\title{
Histological evidence for the cardiac safety of high-dose pegylated liposomal doxorubicin in a patient with HIV- associated Kaposi sarcoma: a case report and literature review
}

Ayaka Ishihara', Shuji Hatakeyama ${ }^{1,2^{*}}$, Jun Suzuki ${ }^{1}$, Yusuke Amano $^{3}$, Teppei Sasahara ${ }^{1,4}$, Masaki Toshima ${ }^{1}$ and Yuji Morisawa'

\begin{abstract}
Background: Pegylated liposomal doxorubicin plays an important role in the treatment of patients with severe refractory human immunodeficiency virus (HIV)-associated Kaposi sarcoma (KS). High cumulative doses of conventional doxorubicin exceeding $500 \mathrm{mg} / \mathrm{m}^{2}$ are known to cause cardiac toxicity. However, the safe cumulative dose of pegylated liposomal doxorubicin is unclear.

Case presentation: A 40-year-old Japanese man with HIV infection presented with pain, edema, and multiple skin nodules on both legs which worsened over several months. He was diagnosed with HIV-associated KS. He received long-term pegylated liposomal doxorubicin combined with antiretroviral therapy for advanced, progressive KS. The cumulative dose of pegylated liposomal doxorubicin reached $980 \mathrm{mg} / \mathrm{m}^{2}$. The patient's left ventricular ejection fraction remained unchanged from baseline during treatment. After he died as a result of cachexia and wasting, caused by recurrent sepsis and advanced KS, an autopsy specimen of his heart revealed little or no evidence of histological cardiac damage. We also conducted a literature review focusing on histological changes of the myocardium in patients treated with a cumulative dose of pegylated liposomal doxorubicin exceeding $500 \mathrm{mg} / \mathrm{m}^{2}$.

Conclusions: This case report and literature review suggest that high $\left(>500 \mathrm{mg} / \mathrm{m}^{2}\right)$ cumulative doses of pegylated liposomal doxorubicin may be used without significant histological/clinical cardiac toxicity in patients with HIVassociated KS.
\end{abstract}

Keywords: Human immunodeficiency virus infection, Kaposi sarcoma, Kaposi sarcoma-associated herpesvirus inflammatory cytokine syndrome, Pegylated liposomal doxorubicin, Cardiac toxicity

\section{Background}

Kaposi sarcoma (KS) is a major life-threatening complication associated with human immunodeficiency virus (HIV) infection. KS is caused by human herpesvirus 8 (HHV-8)/KS-associated herpesvirus (KSHV) infection, which also causes primary effusion lymphoma and HIV-

\footnotetext{
* Correspondence: shatake-tky@umin.ac.jp

'Division of Infectious Diseases, Jichi Medical University Hospital, 3311-1 Yakushiji, Shimotsuke-shi, Tochigi 329-0498, Japan

${ }^{2}$ Division of General Internal Medicine, Jichi Medical University Hospital,

3311-1 Yakushiji, Shimotsuke-shi, Tochigi 329-0498, Japan

Full list of author information is available at the end of the article
}

associated multicentric Castleman disease. The incidence of HIV-associated KS has decreased and prognosis has improved dramatically since the development and introduction of antiretroviral therapy (ART). It has been reported that $35 \%$ of all patients with HIV-associated KS have an advanced form of the disease, such as visceral involvement, tumor-associated edema or ulceration, or extensive oral KS [1].

Systemic chemotherapy combined with ART is recommended for advanced KS, and pegylated liposomal doxorubicin is the first-line drug used for this purpose.

(c) The Author(s). 2019 Open Access This article is distributed under the terms of the Creative Commons Attribution 4.0 International License (http://creativecommons.org/licenses/by/4.0/), which permits unrestricted use, distribution, and reproduction in any medium, provided you give appropriate credit to the original author(s) and the source, provide a link to the Creative Commons license, and indicate if changes were made. The Creative Commons Public Domain Dedication waiver (http://creativecommons.org/publicdomain/zero/1.0/) applies to the data made available in this article, unless otherwise stated. 
However, there is an emerging problem of patients who do not respond to the combination of chemotherapy and ART. A questionnaire surveillance study of HIVassociated KS in Japan showed that approximately $10 \%$ of patients had KS that was refractory to pegylated liposomal doxorubicin therapy combined with ART [2]. In patients with advanced HIV-associated KS, published studies have shown response rates to pegylated liposomal doxorubicin therapy of 46-76\% [3, 4]. For these patients with refractory $\mathrm{KS}$, decisions need to be made regarding a change in therapy to paclitaxel, a secondline agent, or continuation of pegylated liposomal doxorubicin for an extended period [5].

The main concern regarding long-term use of doxorubicin is dose-dependent cardiac toxicity. Based on a combined index of signs, symptoms, and decline in left ventricular ejection fraction (LVEF), cardiac toxicity is estimated to occur in 3-20\% patients receiving cumulative doxorubicin doses of $300-500 \mathrm{mg} / \mathrm{m}^{2}$. The risk of developing congestive heart failure (CHF) increases dramatically with cumulative doses of doxorubicin $>400$ $\mathrm{mg} / \mathrm{m}^{2}$ [6]. Therefore, a pegylated liposomal formulation of doxorubicin was developed, which poses significantly lower risk of cardiotoxicity than conventional doxorubicin [7]. However, similar to conventional doxorubicin, a total cumulative dose $>500 \mathrm{mg} / \mathrm{m}^{2}$ is not recommended because of the risk of developing CHF [8]. However, there is little evidence to support the discontinuation of pegylated liposomal doxorubicin therapy for patients with refractory $\mathrm{HIV}$-associated $\mathrm{KS}$ when the cumulative dose exceeds $500 \mathrm{mg} / \mathrm{m}^{2}$.

Here, we present a case of severe, refractory HIVassociated KS treated with a high cumulative dose of pegylated liposomal doxorubicin after showing no response to second-line therapy with paclitaxel. The patient eventually died as a result of wasting and cachexia caused by recurrent sepsis and advanced $\mathrm{KS}$, after receiving a cumulative dose of $980 \mathrm{mg} / \mathrm{m}^{2}$ of pegylated liposomal doxorubicin, and had no histological evidence of myocardial damage on autopsy. We also review the literature on other patients treated with cumulative doses of $\geq 500 \mathrm{mg} / \mathrm{m}^{2}$, and who received myocardial biopsy. We acknowledge that we have reported the present case as a clinical image demonstrating ${ }^{18} \mathrm{~F}$-fluorodeoxyglucose-positron emission tomography and gallium-67 scintigraphy findings of KS lesions in the lower extremities [9].

\section{Case presentation}

A 40-year-old Japanese man, who had had sex with men, presented with pain, edema, and multiple skin nodules on both legs which had worsened over several months. Although he had been diagnosed with HIV infection 20 years previously, he had not sought medical treatment. On admission, he was afebrile. His legs had hardened with numerous black nodules on dark skin. Multiple lymph nodes were palpable, including cervical, submandibular, submental, supraclavicular, and axillary lymph nodes. Breath sounds in the left lung were decreased. A chest X-ray showed bilateral pleural effusion. His CD4 T-lymphocyte count was 170 cells $/ \mu \mathrm{L}$ and his HIV-1 RNA load was 68,000 copies/mL. His serum C-reactive protein level was $3.1 \mathrm{mg} / \mathrm{dL}$ and he had an HHV-8 DNA load of 6500 copies $/ 10^{6}$ leukocytes in whole blood samples.

A cytological analysis of pleural effusion revealed no atypical lymphocytes suggestive of primary effusion lymphoma. Biopsy specimens of the skin nodules and submental lymph node revealed $\mathrm{KS}$, identified by the presence of whorls of spindle-shaped cells and positive immunostaining for $\mathrm{HHV}-8$ and D2-40. There was no clinical or pathological evidence suggestive of multicentric Castleman disease. The patient was diagnosed with $\mathrm{HIV}$-associated KS with a tumor Stage 1, immune system Stage 1, and systemic illness Stage 1, according to the AIDS Clinical Trials Group Oncology Committee staging criteria [10]. He met the criteria for KSassociated herpesvirus inflammatory cytokine syndrome (KICS). Two weeks after starting ART (raltegravir and tenofovir disoproxil fumarate/emtricitabine), chemotherapy with pegylated liposomal doxorubicin at a dose of $20 \mathrm{mg} / \mathrm{m}^{2}$ every 2 weeks was initiated for KS. His LVEF before initiation of chemotherapy was $60 \%$. After 16 courses of pegylated liposomal doxorubicin, the cumulative dose was $320 \mathrm{mg} / \mathrm{m}^{2}$. His pleural effusion had decreased, and leg edema and skin nodules had gradually improved. His LVEF was monitored and did not decrease during chemotherapy.

In order to avoid cardiac toxicity associated with long-term use of pegylated liposomal doxorubicin, we switched his therapy to paclitaxel $\left(100 \mathrm{mg} / \mathrm{m}^{2}\right.$ every 2 weeks). However, his right pleural effusion increased rapidly after two courses of paclitaxel. Repeated cytology of pleural fluid revealed no atypical lymphocytes. As an echocardiogram indicated that his LVEF had not changed significantly from baseline (62\% from 60\%), we switched back to pegylated liposomal doxorubicin treatment. At this point, his right pleural effusion began to gradually decrease again. His skin nodules became less marked, but he developed recurrent blisters on his thighs and knees, which required application of topical antiseptics such as silver sulfadiazine cream. He did not experience any palmarplanter erythrodysthesia, thrombocytopenia, or severe neutropenia during the treatment. Cardiac scintigraphy using ${ }^{123} \mathrm{I}-\beta$-methyl-P-iodophenyl-pentadecanoic acid (BMIPP), performed after 42 courses of pegylated liposomal doxorubicin, showed no myocardial metabolic defect (Fig. 1). 


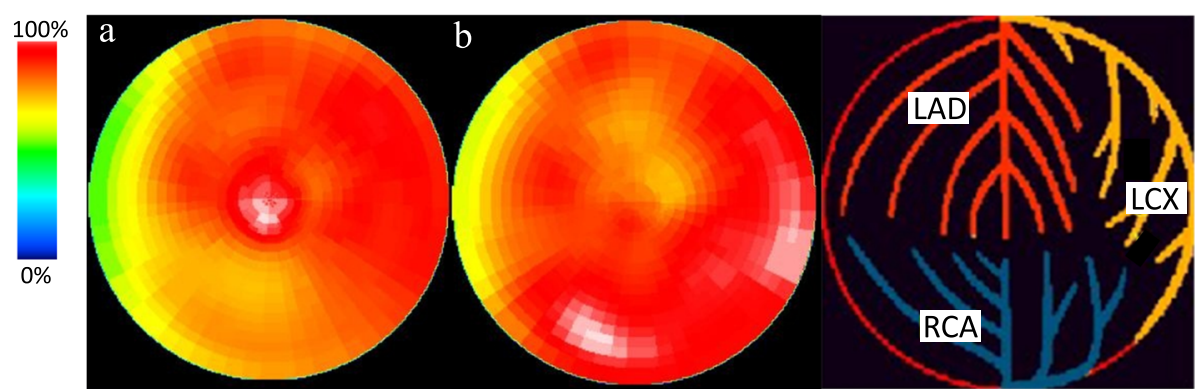

Fig. 1 Images of ${ }^{123}$ I-BMIPP myocardial scintigraphy. ${ }^{123}$ I- $\beta$-methyl-P-iodophenyl-pentadecanoic acid (BMIPP) cardiac scintigraphy obtained after 42 courses of pegylated liposomal doxorubicin showed no reduction of ${ }^{123}$ I- BMIPP uptake. (a) Early phase (30 min after intravenous injection); (b) Delayed phase ( $4 \mathrm{~h}$ after intravenous injection)

He underwent a total of 49 courses of pegylated liposomal doxorubicin, with a total cumulative dose of $980 \mathrm{mg} / \mathrm{m}^{2}$. After the 49 courses he developed septic osteoarthritis of his right hip, and pegylated liposomal doxorubicin was discontinued. He subsequently developed new skin nodules appeared on his neck, and his systemic edema progressively worsened. He developed recurrent sepsis caused by cellulitis of the lower extremities via non-intact skin, as a result of the reappearance of the KS lesions. Two months after discontinuation of pegylated liposomal doxorubicin, he died as a result of wasting and cachexia caused by recurrent sepsis and advanced KS. At the time of his death, his CD4 T-lymphocyte count was 165 cells/ $\mu \mathrm{L}$ and his HIV load was undetectable. An autopsy was performed, and it revealed systemic invasion of KS, particularly in the bilateral lung and pleura, soft tissue of the pelvis, and skin in the groin area. There were no pathological findings of other malignancies, including lymphoma or multicentric Castleman disease. The adipose tissue and skeletal muscle of the whole body were extremely atrophic, characteristic of cachexia. Histological examination of his heart (Fig. 2) showed preservation of myofibrils and myocytes, with little inflammatory cell infiltration, corresponding to 0.5 points on the Billingham scale; a widely used endomyocardial biopsy score for grading anthra cycline-induced myocardial damage (Appendix). This finding indicated that he had not experienced histological cardiotoxicity as a result of the $980 \mathrm{mg} / \mathrm{m}^{2} \mathrm{cu}-$ mulative dose of pegylated liposomal doxorubicin that he had received.

\section{Discussion and conclusions}

The most reliable indicator of cardiac damage is histological change, and the Billingham scale (Appendix) has a high sensitivity for detecting early cardiac damage [11]. Myocardial biopsies from patients who develop conventional doxorubicin-induced CHF typically have a Billingham score of $3.0[12,13]$. In this patient, there was little evidence of histological or clinical cardiac toxicity, even after receiving a total cumulative dose of $980 \mathrm{mg} / \mathrm{m}^{2}$ pegylated liposomal doxorubicin for HIV-associated KS.

Liposome encapsulation reduces the cardiac toxicity of doxorubicin while preserving its antitumor effect [14]. In a trial for metastatic breast carcinoma, non-pegylated liposomal doxorubicin showed lesser cardiac toxicity than that of conventional doxorubicin; CHF occurred in 2 and $8 \%$ of patients treated with non-pegylated liposomal doxorubicin and conventional doxorubicin, respectively [15]. Pegylation of liposomal doxorubicin reduces uptake by reticuloendothelial system (liver or spleen), and
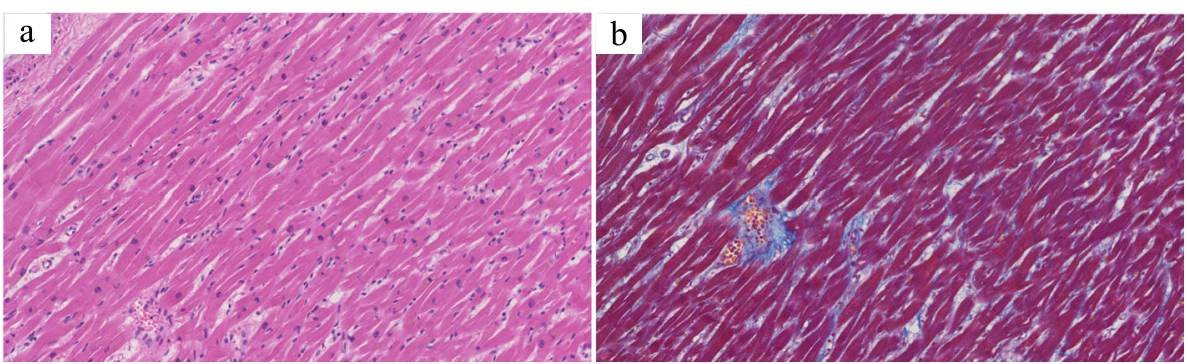

Fig. 2 Myocardial histopathology of the autopsy specimen. (a) Preserved myofibrils or myocytes with little inflammatory cell infiltration were observed in hematoxylin and eosin stained tissue (original magnification $\times 20$ ); (b) No increase in collagen between myocytes observed on azan stained tissue (original magnification $\times 20$ ) 
therefore maintains high blood concentrations of the drug [16]. In a study of 509 women with metastatic breast cancer, cardiac toxicity (defined by declining LVEF) during treatment and follow up was less frequently associated with pegylated liposomal doxorubicin than with conventional doxorubicin; cardiotoxicity developed in $4 \%$ versus $19 \%$ of cases, cardiotoxicity with signs and symptoms of CHF in $0 \%$ versus $4 \%$ of cases, and cardiotoxicity without signs and symptoms of CHF in $4 \%$ versus $15 \%$ of cases, respectively [7]. Several trials and case reports of breast and gynecological cancer have shown that patients treated with pegylated liposomal doxorubicin showed no signs or symptoms of CHF, even when they received a cumulative dose of pegylated liposomal doxorubicin $>1000 \mathrm{mg} / \mathrm{m}^{2}$ [17-21]. In contrast, $0-5 \%$ of patients experienced a reduction in LVEF of $\geq 20 \%$ relative to baseline [17-20]. There are currently limited data regarding the cardiac safety/toxicity of high cumulative doses of pegylated liposomal doxorubicin in patients with HIV-associated KS. In one study of 52 individuals with HIV-associated KS, none of the participants developed clinical heart failure after a mean cumulative dose of $456 \mathrm{mg} / \mathrm{m}^{2}$ pegylated liposomal doxorubicin [22].

Radiotherapy that involves incidental exposure of the heart is one of the risk factors for developing doxorubicin-induced cardiotoxicity. A previous study showed that the cumulative anthracycline dose and average radiation dose to the heart were significant independent factors associated with cardiac failure [23].

It has been proposed that LVEF may not accurately indicate cardiotoxicity in adult patients receiving high $\mathrm{cu}-$ mulative doses of pegylated liposomal doxorubicin [24].
We therefore conducted a literature review that focused on histological changes of the myocardium in patients treated with $\geq 500 \mathrm{mg} / \mathrm{m}^{2}$ of pegylated liposomal doxorubicin, in order to assess the evidence that high cumulative doses of this drug formulation can be administered without cardiac toxicity. As shown in Table 1, we identified 14 patients reported to have received $\geq 500 \mathrm{mg} / \mathrm{m}^{2}$ pegylated liposomal doxorubicin, who underwent myocardial biopsy for HIV-associated KS (7 patients), breast cancer (5 patients), or ovarian cancer ( 2 patients). The median cumulative pegylated liposomal doxorubicin dose among these patients was $708 \mathrm{mg} / \mathrm{m}^{2}$ (range, $500-1485 \mathrm{mg} / \mathrm{m}^{2}$ ). The Billingham scores of all patients were under 1.5 , indicating that no patient had significant histological myocardial damage.

KICS is a recently described syndrome that is characterized by severe inflammatory cytokine dysregulation attributed to lytic activation of HHV-8/KSHV. Proposed diagnostic criteria for KICS require that all of the following conditions be met: (1) At least two symptoms, laboratory, or radiographic abnormalities (including fever, fatigue, edema, cachexia, respiratory symptoms, gastrointestinal disturbance, arthralgia and myalgia, altered mental state, neuropathy, cytopenia, hypoalbuminemia, hyponatremia, lymphadenopathy, hepatosplenomegaly, and effusions of the body cavities); (2) evidence of systemic inflammation (elevated C-reactive protein); (3) elevated KSHV viral load in peripheral blood mononuclear cells; and (4) exclusion of multicentric Castleman disease [28]. Since KICS may be associated with severe inflammatory symptoms, a poor clinical response to treatment, and high mortality, it is important to recognize that individuals with severe, refractory, or recurrent KS that does

Table 1 Endomyocardial biopsy scores of patients treated with high cumulative doses of pegylated liposomal doxorubicin

\begin{tabular}{|c|c|c|c|c|c|c|c|}
\hline Patient & Age & Sex & Underlying disease & Prior doxorubicin dose $\left(\mathrm{mg} / \mathrm{m}^{2}\right)$ & Cumulative PLD dose $\left(\mathrm{mg} / \mathrm{m}^{2}\right)$ & Billingham score & Reference \\
\hline 1 & Unknown & M & KS & 0 & 500 & 1 & {$[25]$} \\
\hline 2 & Unknown & M & KS & 0 & 541 & 0 & {$[25]$} \\
\hline 3 & 35 & F & Breast cancer $^{a}$ & 180 & 564 & 0.5 & [26] \\
\hline 4 & Unknown & M & KS & 0 & 578 & 0 & [25] \\
\hline 5 & Unknown & M & KS & 0 & 610 & 0.5 & [25] \\
\hline 6 & 54 & $F$ & Breast cancer $^{\mathrm{a}}$ & 0 & 675 & 0.5 & [27] \\
\hline 7 & 47 & $\mathrm{~F}$ & Breast cancer ${ }^{a}$ & 0 & 685 & 0 & [26] \\
\hline 8 & 66 & $\mathrm{~F}$ & Ovarian cancer & 0 & 730 & 0 & [26] \\
\hline 9 & Unknown & M & KS & 0 & 780 & 0 & [25] \\
\hline 10 & Unknown & M & KS & 0 & 801 & 0.5 & [25] \\
\hline 11 & Unknown & M & KS & 0 & 860 & 0 & [25] \\
\hline 12 & 36 & $\mathrm{~F}$ & Ovarian cancer & 375 & 952 & 0 & [26] \\
\hline 13 & 52 & $F$ & Breast cancer ${ }^{a}$ & 360 & 1320 & 1.5 & [26] \\
\hline 14 & 49 & $\mathrm{~F}$ & Breast cancer & 0 & 1485 & 1 & {$[26]$} \\
\hline
\end{tabular}

Abbreviations: $M$ Male, F Female, KS Kaposi sarcoma, PLD Pegylated liposomal doxorubicin

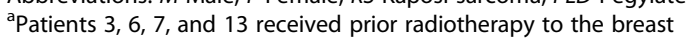


not respond to standard treatment, need to be screened for KICS in addition to primary effusion lymphoma and multicentric Castleman disease.

In conclusion, both our patient and previous reports suggest that a cumulative dose of pegylated liposomal doxorubicin exceeding $500 \mathrm{mg} / \mathrm{m}^{2}$ is not necessarily associated with significant clinical/histological cardiac damage. Because alternative therapies are limited, longterm and multi-course pegylated liposomal doxorubicin treatment is occasionally required for refractory HIVassociated KS. Further studies are warranted to identify the cumulative dose of pegylated liposomal doxorubicin that is the threshold for clinical/histological cardiac toxicity in patients with HIV-associated KS.

\section{Appendix}

Morphologic grades for anthracycline-induced myocardial toxicity according to the Billingham scoring system $[11,12]$

\begin{tabular}{ll}
\hline Grade & Morphology \\
\hline 0 & Normal myocardial ultrastructural morphology \\
0.5 & $\begin{array}{l}\text { Not completely normal but no evidence of anthracycline-specific } \\
\text { damage }\end{array}$ \\
1 & $\begin{array}{l}\text { Isolated myocytes affected and/or early myofibrillar loss; damage } \\
\text { to }<5 \% \text { of all cells }\end{array}$ \\
$1.5 \quad \begin{array}{l}\text { Changes similar to those in grade } 1 \text { except damage involves } \\
6-15 \% \text { of all cells }\end{array}$ & $\begin{array}{l}\text { Clusters of myocytes affected by microfibrillar loss and/or } \\
\text { vacuolization, with damage 16-25\% of all cells }\end{array}$ \\
2.5 & $\begin{array}{l}\text { Many myocytes (26-35\% of all cells) affected by vacuolization } \\
\text { and/or myofibrillar loss }\end{array}$ \\
& Severe, diffuse myocyte damage (>35\% of all cells)
\end{tabular}

\section{Abbreviations}

ART: Antiretroviral therapy; BMIPP: ${ }^{123} 1-\beta$-methyl-P-iodophenyl-pentadecanoic acid; CHF: Congestive heart failure; HHV-8: Human herpesvirus 8; HIV: Human immunodeficiency virus; KICS: Kaposi sarcoma herpesvirus-associated inflammatory cytokine syndrome; KS: Kaposi sarcoma; KSHV: Kaposi sarcomaassociated herpesvirus; LVEF: Left ventricular ejection fraction

\section{Acknowledgements}

Not applicable.

\section{Authors' contributions}

$\mathrm{Al}, \mathrm{JS}$, and $\mathrm{SH}$ conceived and conducted this study and drafted the manuscript. JS, TS, MT, and YM cared for the patient and drafted the case report. YA provided histological diagnoses and images of this patient. Al and SH critically revised the entire manuscript for intellectual content. All authors read and approved the final manuscript.

\section{Funding}

The authors declare that they received no funding for this study.

\section{Availability of data and materials}

All data containing relevant information to support these findings are included in the manuscript.

Ethics approval and consent to participate Not applicable.

\section{Consent for publication}

The parents of the patient provided written informed consent for publication of this report according to the patient's consent given prior to death.

\section{Competing interests}

The authors declare that they have no competing interests.

\section{Author details}

'Division of Infectious Diseases, Jichi Medical University Hospital, 3311-1 Yakushiji, Shimotsuke-shi, Tochigi 329-0498, Japan. ${ }^{2}$ Division of General Internal Medicine, Jichi Medical University Hospital, 3311-1 Yakushiji, Shimotsuke-shi, Tochigi 329-0498, Japan. ${ }^{3}$ Department of Diagnostic Pathology, Jichi Medical University Hospital, 3311-1 Yakushiji, Shimotsuke-shi, Tochigi 329-0498, Japan. ${ }^{4}$ Department of Infection and Immunity, School of Medicine, Jichi Medical University, 3311-1 Yakushiji, Shimotsuke-shi, Tochigi 329-0498, Japan.

Received: 28 June 2019 Accepted: 24 September 2019

Published online: 15 October 2019

\section{References}

1. Bower M, Dalla Pria A, Coyle C, Andrews E, Tittle V, Dhoot S, et al. Prospective stage-stratified approach to AIDS-related Kaposi's sarcoma. J Clin Oncol. 2014;32:409-14.

2. Katano H, Imamura A, Kato H, Ozawa K, Nagata N, Teruya K, et al. Diagnosis and guidance on HHV-8 related diseases such as AIDS related Kaposi sarcoma. http://www.acc.go.jp/doctor/010/020/HHV8_tebiki201403.pdf [accessed 17 May 2019].

3. Cianfrocca M, Lee S, Von Roenn J, Tulpule A, Dezube BJ, Aboulafia DM, et al. Randomized trial of paclitaxel versus pegylated liposomal doxorubicin for advanced human immunodeficiency virus-associated Kaposi sarcoma: evidence of symptom palliation from chemotherapy. Cancer. 2010;116:3969.

4. Martin-Carbonero L, Barrios A, Saballs P, Sirera G, Santos J, Palacios R, et al. Pegylated liposomal doxorubicin plus highly active antiretroviral therapy versus highly active antiretroviral therapy alone in HIV patients with Kaposi's sarcoma. AIDS. 2004;18:1737-40.

5. Tulpule A, Groopman J, Saville MW, Harrington W Jr, Friedman-Kien A, Espina BM, et al. Multicenter trial of low-dose paclitaxel in patients with advanced AIDS-related Kaposi sarcoma. Cancer. 2002;95:147-54.

6. Prescribing Information for DOXORUBICIN HYDROCHLORIDE. U.S. Food and Drug Administration. https://www.accessdata.fda.gov/drugsatfda_docs/ label/2013/050467s073lbl.pdf [accessed 17 May 2019].

7. O'Brien ME, Wigler N, Inbar M, Rosso R, Grischke E, Santoro A, et al. CAELYX breast Cancer study group. Reduced cardiotoxicity and comparable efficacy in a phase III trial of pegylated liposomal doxorubicin HCl (CAELYX/Doxil) versus conventional doxorubicin for first-line treatment of metastatic breast cancer. Ann Oncol. 2004;15:440-9.

8. Prescribing Information for DOXIL. U.S. Food and Drug Administration. https://www.accessdata.fda.gov/drugsatfda_docs/label/2016/050718s051lbl. pdf [accessed 17 May 2019].

9. Suzuki J, Sasahara T, Toshima M, Norizuki M, Onishi T, Okabe T, et al. Usefulness of ${ }^{18} \mathrm{~F}$-Fluorodeoxyglucose-position emission tomography with computed tomography and gallium-67 scintigraphy for detection of Kaposi sarcoma lesions in a 40-year-old Japanese man with AIDS. IDCases. 2015;2:68-9.

10. Krown SE, Metroka C, Wernz JC. Kaposi's sarcoma in the acquired immune deficiency syndrome: a proposal for uniform evaluation, response, and staging criteria. AIDS Clinical Trials Group oncology committee. J Clin Oncol. 1989;7:1201-7.

11. Rahman AM, Yusuf SW, Ewer MS. Anthracycline-induced cardiotoxicity and the cardiac-sparing effect of liposomal formulation. Int J Nanomedicine. 2007:2:567-83.

12. Billingham ME, Mason JW, Bristow MR, Daniels JR. Anthracycline cardiomyopathy monitored by morphologic changes. Cancer Treat Rep. 1978;62:865-72

13. Bristow MR, Mason JW, Billingham ME, Daniels JR. Doxorubicin cardiomyopathy: evaluation by phonocardiography, endomyocardial biopsy, and cardiac catheterization. Ann Intern Med. 1978;88:168-75.

14. Tardi PG, Boman NL, Cullis PR. Liposomal doxorubicin. J Drug Target. 1996:4: 129-40. 
15. Harris L, Batist G, Belt R, Rovira D, Navari R, Azarnia N, et al. TLC D-99 study group. Liposome-encapsulated doxorubicin compared with conventional doxorubicin in a randomized multicenter trial as first-line therapy of metastatic breast carcinoma. Cancer. 2002:94:25-36.

16. Klibanov AL, Maruyama K, Torchilin VP, Huang L. Amphipathic polyethylenglycols effectively prolong the circulation time of liposomes. FEBS Lett. 1990;268:235-7.

17. Gordon AN, Fleagle JT, Guthrie D, Parkin DE, Gore ME, Lacave AJ. Recurrent epithelial ovarian carcinoma: a randomized phase III study of pegylated liposomal doxorubicin versus topotecan. J Clin Oncol. 2001;19:3312-22.

18. Uyar D, Kulp B, Peterson G, Zanotti K, Markman M, Belinson J. Cardiac safety profile of prolonged ( $>$ or $=6$ cycles) pegylated liposomal doxorubicin administration in patients with gynecologic malignancies. Gynecol Oncol. 2004;94:147-51.

19. Collins Y, Lele S. Long-term pegylated liposomal doxorubicin use in recurrent ovarian carcinoma. J Natl Med Assoc. 2005;97:1414-6.

20. Kesterson JP, Odunsi K, Lele S. High cumulative doses of pegylated liposomal doxorubicin are not associated with cardiac toxicity in patients with gynecologic malignancies. Chemotherapy. 2010;56:108-11.

21. Rabinovich A, Ramanakumar AV, Lau S, Gotlieb WH. Prolonged pegylated liposomal doxorubicin treatment for recurrent pelvic cancers: a feasiability study. Acta Obstet Gynecol Scand. 2015;94:776-80,

22. Hengge UR, Esser S, Rudel HP, Goos M. Long-term chemotherapy of HIVassociated Kaposi's sarcoma with liposomal doxorubicin. Eur J Cancer. 2001; 37:878-83.

23. Pein F, Sakiroglu O, Dahan M, Lebidois J, Merlet P, Shamsaldin A, et al. Cardiac abnormalities 15 years and more after adriamycin therapy in 229 childhood survivors of a solid tumour at the Institut Gustave Roussy. Br J Cancer. 2004;91:37-44.

24. Skubitz KM, Blaes AH, Konety SH, Francis GS. Cardiac safety profile of patients receiving high cumulative doses of pegylated-liposomal doxorubicin: use of left ventricular ejection fraction is of unproven value. Cancer Chemother Pharmacol. 2017:80:787-98

25. Berry G, Billingham M, Alderman E, Richardson P, Torti F, Lum B, et al. The use of cardiac biopsy to demonstrate reduced cardiotoxicity in AIDS Kaposi's sarcoma patients treated with pegylated liposomal doxorubicin. Ann Oncol. 1998:9:711-6.

26. Gabizon AA, Lyass O, Berry GJ, Wildgust M. Cardiac safety of pegylated liposomal doxorubicin (Doxil/Caelyx) demonstrated by endomyocardial biopsy in patients with advanced malignancies. Cancer Investig. 2004;22: 663-9.

27. Safra T, Muggia F, Jeffers S, Tsao-Wei DD, Groshen S, Lyass O, et al. Pegylated liposomal doxorubicin (doxil): reduced clinical cardiotoxicity in patients reaching or exceeding cumulative doses of $500 \mathrm{mg} / \mathrm{m}^{2}$. Ann Oncol. 2000;11:1029-33.

28. Polizzotto MN, Uldrick TS, Hu D, Yarchoan R. Clinical manifestations of Kaposi sarcoma herpesvirus lytic activation: multicentric Castleman disease (KSHV-MCD) and the KSHV inflammatory cytokine syndrome. Front Microbiol. 2012;3:73.

\section{Publisher's Note}

Springer Nature remains neutral with regard to jurisdictional claims in published maps and institutional affiliations.

Ready to submit your research? Choose BMC and benefit from:

- fast, convenient online submission

- thorough peer review by experienced researchers in your field

- rapid publication on acceptance

- support for research data, including large and complex data types

- gold Open Access which fosters wider collaboration and increased citations

- maximum visibility for your research: over $100 \mathrm{M}$ website views per year

At $\mathrm{BMC}$, research is always in progress.

Learn more biomedcentral.com/submissions 